\title{
A Study on Binder Jetting of High Dimensional Stability Alloy
}

\author{
N. Azurmendi ${ }^{1}$, A. Lores ${ }^{1}$, I. Agote ${ }^{1}$ \\ 1- Fundación Tecnalia Research \& Innovation, Mikeletegi Pasealekua 2, Parque Tecnológico de San \\ Sebastian, 20009 Donostia / San Sebastian
}

\begin{abstract}
This work opens a new pathway to fabricate high dimensional stability Invar36 aerospace devices with Binder Jetting technology, for applications where temperature fluctuations directly interfere in the correct performance of high sensibility systems. Since full density part fabrication is one of the main ongoing challenges for Binder Jetting, the leading objective of this work is to study and optimise the main process parameters to increase the final density of Invar36 printed parts. Microstructural analysis and obtained density and CTE values, confirmed the feasibility to fabricate Invar36 parts.
\end{abstract}

Keywords: Additive manufacturing, Binder Jetting, aerospace, Invar36, CTE

\section{Introduction}

Invar36, Fe-36wt.\% Ni alloy, is well known for its low coefficient of thermal expansion (CTE) below its Curie temperature $\left(230^{\circ} \mathrm{C}\right)$ and for its excellent mechanical properties in cryogenic environment $[1,2]$. Due to these features, it has been widely used as highly reliable and high precision material in components where high dimensional stability is required. The applications include space equipment, precision instruments, optical devices, advanced composite moulds for aerospace industry, special electronic housings, etc. Conventionally, Invar36 components are manufactured by machining which is expensive and difficult due to its softness and high plasticity. Consequently, machining bulk Invar 36 materials into complex shapes is particularly challenging.

Binder Jetting (BJ), due to its capability to fabricate complex freeform geometries directly from Computer- Aided Design (CAD) models, is considered one of the best near-neat-shape manufacturing technologies for processing metallic/ceramic materials. It is an especially recommended Additive Manufacturing (AM) technology for processing materials with low machinability and also materials whose thermal properties are challenging to manage for laser and electron beam based AM processes, producing high complexity near-net-shapes that require minimum machining.

Binder jetting is an AM process in which a liquid bonding agent is selectively deposited to join powder particles [3]. A layer of powder is spread across the building platform and binder is selectively deposited based on CAD model information in each layer. This process is repeated until the final geometry is achieved. In the case of metal binder jetting systems, the entire powder bed is "cured" to burn off the binder and to retrieve the final part. Subsequently, the part is sintered to create metallurgical bonding and often infiltrated with a material of lower melting point to achieve higher density [4].

The primary challenge in fabricating metal parts with binder jetting is to achieve a fully dense product following the sintering postprocess. Pores typically exist in sintered ceramics or metals fabricated in binder jetting $[5,6]$. Porosity is challenging to eliminate during sintering because achievable low powder bed packing density and the difficulty to process ultra-fine powders. Coarse powders are more suitable for spreading and packing purposes, but the large particles significantly inhibit sintering densification due to the low sintering driving force. Fine powders are preferred for sintering; however, the powder bed is typically poorly packed, and the powder recoating can be difficult due to powder's low flowability and agglomeration tendencies. Fabricating highly dense metal parts in binder jetting without infiltration has been a major focus for binder jetting research. Different approaches have been studied in order to obtain full density via BJ such as the use of bimodal mixtures [7-9], spray-dried granules [10], slurry based powders [11], sintering process (addition of sintering additives, liquid-phase sintering mechanism, pressure-assisted sintering, [7,12] etc), among others. Nevertheless, to the knowledge of the authors, 
there is not any research work that study the influence of the main parameters of BJ process on the obtained final density. Therefore, the aim of this work is to study and optimise the main process parameters to increase the final density of Invar36 printed parts.

\section{Materials and methods}

In this study, gas atomized Invar36 powder supplied by Sandvik Osprey LTD was used. Powder composition and characteristics given by the manufacturer is shown in Table 1. Relatively small powder particle size (D90: $23 \mu \mathrm{m}$ ) was selected for this study due to the higher packing densities achievable, allowing higher densification after sintering process. Powder morphology was analysed by SEM microscopy (Jeol JSM 5910 LV microscope with Oxford Inca 300 EDS accessory) and the graphical PSD of the powder was measured with Laser Difraction Malvern Mastersizer 2000 machine.

\begin{tabular}{lllll}
\hline \multicolumn{5}{l}{ Chemical Analysis (wt \%) } \\
\hline $\mathrm{Fe}$ & $\mathrm{Ni}$ & $\mathrm{Mn}$ & $\mathrm{Si}$ & $\mathrm{C}$ \\
\hline Balanced & 36.3 & 0.12 & 0.03 & 0.01 \\
\hline \multicolumn{5}{l}{ Particle Size Distribution $(\boldsymbol{\mu m})$} \\
\hline $\mathrm{D} 10$ & $\mathrm{D} 50$ & $\mathrm{D} 90$ & \\
\hline 5.8 & 12.3 & 21.9 &
\end{tabular}

Table 1. Chemical composition and PSD of INVAR 36 powder supplied by Sandvik Osprey LTD.

In order to optimize process parameters for increasing final part density, a Taguchi methodology based Fractional Factorial Design of Experiments (DoE) was carried out. Taguchi methodology has been already used on BJ process optimization [13-16]. This straightforward robust design methodology allows analysing multiple parameters in an extremely briefed testing plan in order to reduce process variations, attaining desired quality objectives and cost savings $[17,18]$. Nevertheless, this methodology requires a minimal interaction between factors and lineal variation behaviour for best performance and obtained data significance.

BJ process carried out with ExOne Innovent machine can be divided in four main stages: powder deposition, powder spreading, layer printing and layer drying. Each stage is leaded by several factors and parameters that may affect process stage performance and thus final part quality. In this study, only one parameter from each stage has been selected as DoE factor in order to have a preliminary overall understanding of process stage effect on final part quality. An $L_{9}\left(3^{\wedge} 4\right)$ Taguchi orthogonal array has been selected for this experiment. In this first study the interaction effects between parameters are ignored. Selected four parameters and their levels are shown in Table 2.

Study parameter selection is based on previous research work from literature. It seems that binder saturation level and feed-to-powder ratio (spread powder amount related to layer thickness) are critical parameters to promote both powder/binder interaction and part densification [15]. Thus, saturation level and recoater speed have been selected as DoE factors, while recoater oscillation level was fixed to $1900 \mathrm{rpm}$. According to [14], the thinner the powder bed layer, the better surface finish and part accuracy. Therefore, layer thickness was fixed to its lower limit value of $50 \mu \mathrm{m}$ for this study. Note that powder particle size is recommended to be less than half of layer thickness to assure good packing and spreading of the powder. Finally, roller traverse speed has been fixed to $3 \mathrm{~mm} / \mathrm{s}$. Lower roller traverse speeds increase part quality [5] and process robustness [19].

\begin{tabular}{|l|l|l|l|l|}
\hline \multicolumn{7}{|c|}{ Studied Factors and Levels } \\
\hline Factor & № & Level 1 & Level 2 & Level 3 \\
\hline Saturation (\%) & 1 & 55 & 65 & 75 \\
\hline Recoat Speed (mm/s) & 2 & 60 & 70 & 80 \\
\hline Roller Revolution (rpm) & 3 & 300 & 450 & 600 \\
\hline Drying Time (s) & 4 & 10 & 15 & 20 \\
\hline
\end{tabular}

Table 2. Selected study parameters and their levels for Taguchi experimental trial.

6 cube samples of $20 \mathrm{~mm} \times 20 \mathrm{~mm} \times 5 \mathrm{~mm}$ were printed for each experimental trial. After printing, the fragile "green parts" were cured at $180^{\circ} \mathrm{C}$ during $4 \mathrm{~h}$ and then sintered in a Carbolite GERO vacuum furnace with the following heating profile: heating at $250^{\circ} \mathrm{C} / \mathrm{h}$ from room temperature to $380^{\circ} \mathrm{C}$, holding $2 \mathrm{~h}$ to facilitate the debinding process, heating at $250^{\circ} \mathrm{C} / \mathrm{h}$ up to $1140^{\circ} \mathrm{C}$ with a holding time of $8 \mathrm{~h}$ and then cooling down to room temperature at $250^{\circ} \mathrm{C} / \mathrm{h}$.

Sintered density was measured by Arquimedes methodology using a Mettler AE 240 weight balance and isopropanol-2 as liquid media. Microstructure of the best printed part was analysed by optical 
microscopy. The thermal expansion coefficient was measured by dilatometry using a Linseis L75 platinum series dilatometer. The dimensions of the samples were $17 \mathrm{~mm}$ in length and $5 \mathrm{~mm}$ in diameter after sintering.

\section{Results and discussion}

\subsection{Powder characterisation}

Figure 1 shows particles morphology and cross section of as-received Invar 36 powder. Most of the powder particles show a diameter between $10 \mu \mathrm{m}$ and $20 \mu \mathrm{m}$ and a near-spherical morphology with some satellite particles bonded to surface, inherent to gas atomisation process. Spherical shaped particles allow better packing characteristics than irregular shaped water atomised powder. The powder section reveals the presence of pores within a few particles probably due to gas entrapment during atomisation.
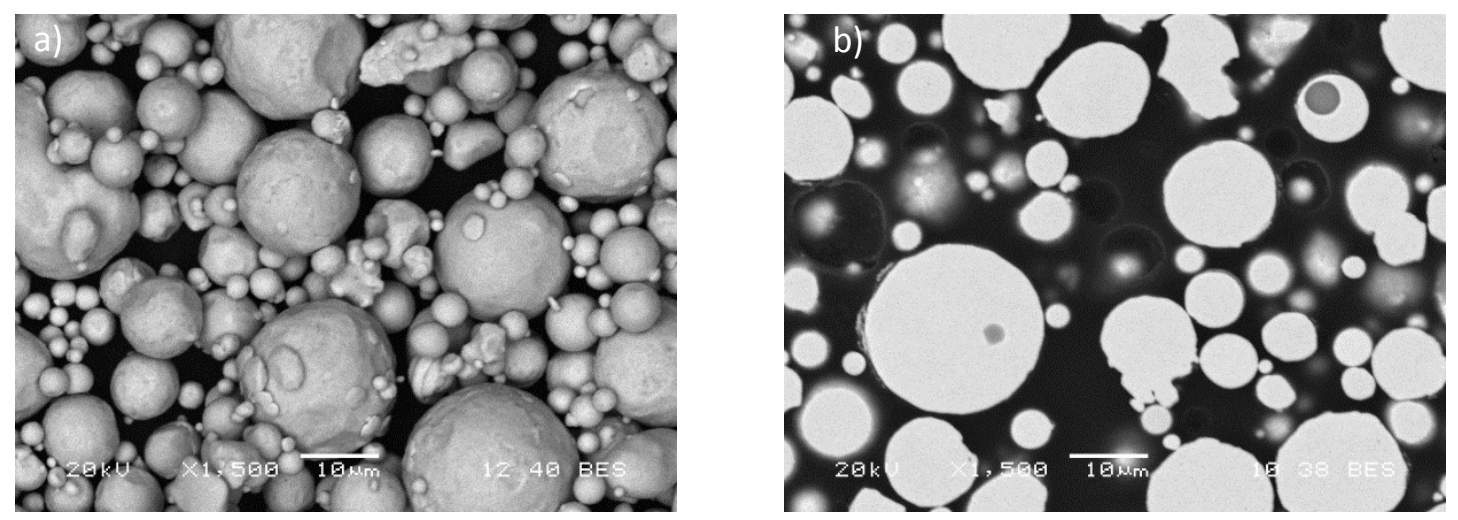

Figure 1. Backscattered electron SEM micrographs of (a) as-received Invar36 powder particles and (b) their cross section.

The graphical PSD of the powder, presented in Figure 2, shows a typical one size log-normal distribution with an average particle size of about 15 microns. Although is well known that bimodal mixtures can achieve higher packing densities than monomodal log-normal distributed powder [20-22] this study is focused on maximize the packing density of monomodal powder through optimal process parameter selection.

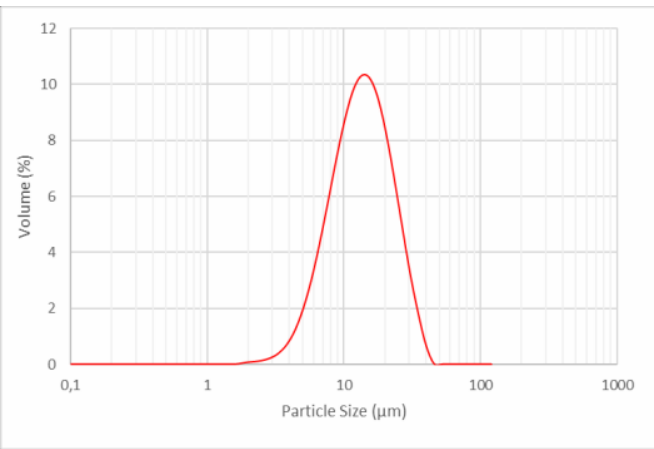

Figure 2. PSD curve of Invar36 powder.

\subsection{Density results and influence of parameters}

Table 3 shows the average relative density, standard deviation and calculated signal-to-noise $(\mathrm{S} / \mathrm{N})$ ratio of each experimental trial. $\mathrm{S} / \mathrm{N}$ ratios of response variable were calculated for the "larger-is-better" quality characteristic with the following equation [17]:

$$
\begin{array}{r}
\left.S / N(d B)=-10 \log _{10} \frac{1}{\sum} \sum^{n}(\underset{i=1}{\stackrel{1}{2}})\right] \\
\rho_{r_{i}}
\end{array}
$$

where $\rho_{r_{i}}$ is the $n^{\text {th }}$ relative density repetition for each trial condition. 
Factors Saturation Recoat Roller Drying $\mathrm{S} / \mathrm{N}$ Speed RPM Time ratios 


\begin{tabular}{|c|c|c|c|c|c|c|c|c|}
\hline & & 1 & 2 & 3 & 4 & $\begin{array}{c}\text { Relative } \\
\text { Density } \\
(\%)\end{array}$ & $\begin{array}{c}\text { Standard } \\
\text { deviation } \\
(\%)\end{array}$ & \\
\hline \multirow{9}{*}{$\frac{\frac{0}{\sigma}}{\frac{\pi}{2}}$} & 1 & 1 & 1 & 1 & 1 & 93.20 & 0.26 & 39.38 \\
\hline & 2 & 1 & 2 & 2 & 2 & 91.97 & 0.34 & 39.27 \\
\hline & 3 & 1 & 3 & 3 & 3 & 91.35 & 0.26 & 39.22 \\
\hline & 4 & 2 & 1 & 2 & 3 & 91.63 & 0.26 & 39.23 \\
\hline & 5 & 2 & 2 & 3 & 1 & 92.68 & 0.45 & 39.33 \\
\hline & 6 & 2 & 3 & 1 & 2 & 91.55 & 0.20 & 39.23 \\
\hline & 7 & 3 & 1 & 3 & 2 & 92.11 & 0.31 & 39.28 \\
\hline & 8 & 3 & 2 & 1 & 3 & 90.61 & 0.33 & 39.15 \\
\hline & 9 & 3 & 3 & 2 & 1 & 92.36 & 0.22 & 39.31 \\
\hline
\end{tabular}

Table 3. Results of relative density, standard deviation and $\mathrm{S} / \mathrm{N}$ ratios of each experimental trial.

Results from Taguchi experiment shown in ANOVA Table 4 indicate that drying time is the parameter with the higher contribution (77\%) to result variation. As can be seen in the average S/N effect from
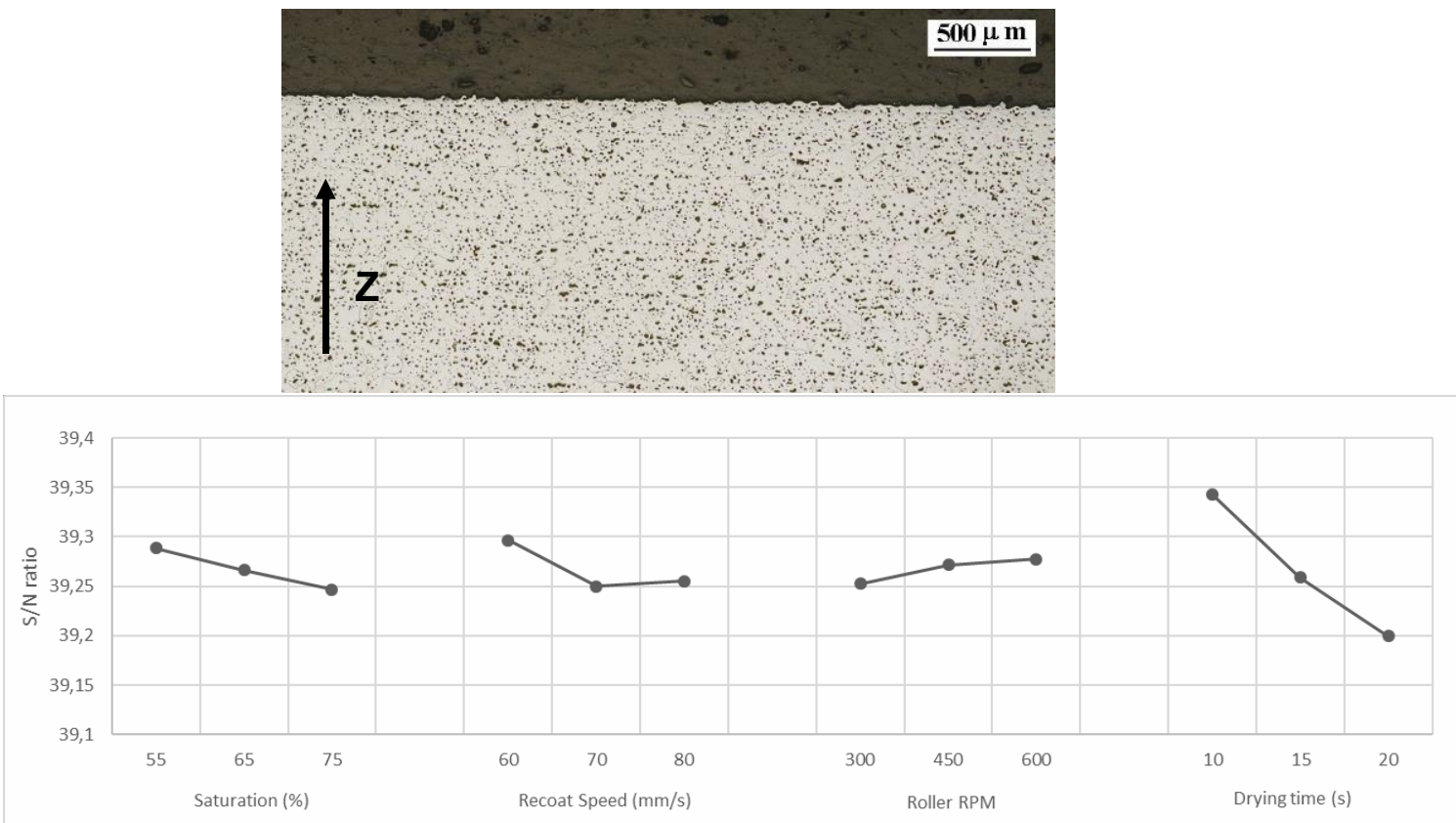

Figure 4, lower drying times increase final part densities. Gaps between each powder layers are critical areas in which porosity is higher due to the interaction between printed part slice and deposited consequent powder layer, as can be observed in Figure 3. Low drying times may contribute to enhance powder adhesion to previously printed part slice. Nevertheless, too low drying times can promote the adhesion of the printed layer to the roller, thus damaging 3D printing trial.

Figure 3. Optical microscope image of an invar36 printed part showing porosity between each layer. 


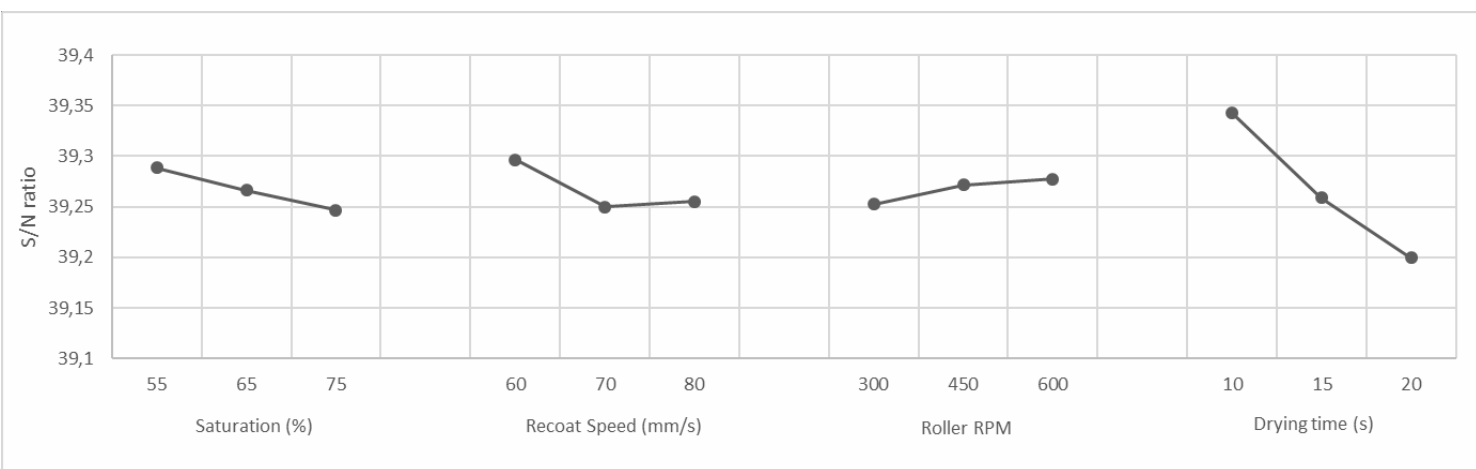

Figure 4. Influence of the parameters on the final density of printed parts.

On the other hand, the rest of parameters seem to have slight contribution to density improvement or variation. Roller Revolution Speed, with a contribution percent to variation of $2,7 \%$, has been pooled as error term, as seen in ANOVA Table 4. F-values of Saturation and Recoater Speed are lower than Fcritical value at $90 \%$ confidence level, meaning no statistical significant difference between those factor level influence on target value. The saturation parameter defines the binder amount deposited within powder particles, and thus it may not have direct influence in powder packing performance.

\begin{tabular}{|c|c|c|c|c|c|c|}
\hline \multicolumn{7}{|l|}{ ANOVA Table } \\
\hline $\begin{array}{l}\text { Source of } \\
\text { variation }\end{array}$ & DOF & $\begin{array}{c}\text { Sum of } \\
\text { Squares, } \mathrm{S}\end{array}$ & Variance, V & $\begin{array}{l}\text { Variance } \\
\text { Ratio, F }\end{array}$ & $\begin{array}{l}\text { Pure Sum of } \\
\text { Squares, } S^{\prime}\end{array}$ & $\begin{array}{c}\text { Percent } \\
\text { Contribution, } \mathbf{P}\end{array}$ \\
\hline Saturation & 2 & 0.002655915 & 0.00132796 & 2.55832308 & 0.00161777 & 4.191059118 \\
\hline Recoat Speed & 2 & 0.003879098 & 0.00193955 & 3.7365592 & 0.00284095 & 7.359886727 \\
\hline \multicolumn{7}{|l|}{ Roller } \\
\hline Revolution & & & & & & \\
\hline Speed & (2) & 0.001038147 & pooled & & & \\
\hline Drying Time & 2 & 0.031027308 & 0.01551365 & 29.8872008 & 0.02998916 & 77.69118458 \\
\hline Error (e) & 2 & 0.001038147 & 0.00051907 & 1 & 0.00415259 & 10.75786957 \\
\hline Total & 8 & 0.038600468 & & & & 100 \\
\hline
\end{tabular}

Table 4. ANOVA table showing the contributions of its factors.

From ANOVA results, the optimal process parameters are summarized in Table 5.

\begin{tabular}{|c|c|c|c|c|}
\hline Parameter & Saturation (1) & Recoat Speed (2) & Roller RPM (3) & Drying Time (4) \\
\hline Level & 55 & 60 & 600 & 10 \\
\hline
\end{tabular}

Table 5. Optimal process parameters obtained from ANOVA analysis.

Estimated performance and its confidence interval at optimum condition is $93.2 \pm 1 \%$ relative density. A confirmation test was run using optimised process parameter levels. Achieved density was $92.7 \%$ with a standard deviation of $0.18 \%$, which is within expected performance value range. Note that although obtained density is not in average the higher between all the experimental trials, its deviation is the smallest one. It is important to highlight that the objective of Taguchi method is to reduce product variance.

\subsection{Microstructure and CTE values}

Microstructure of the Invar36 part using optimal process parameters concluded from ANOVA results is shown in Figure 5. Porosity observed in the OM image (a) is in line with the densification obtained in the process (7.3\% total porosity). Moreover, consistent with Archimedes results (open porosity of $0.7 \pm 0.1 \%$ ), nearly the totality of the porosity corresponds to closed porosity. On the other hand, microstructure reveals a grain growth during sintering process exhibiting grain sizes around 150-200 $\mu \mathrm{m}$. As stated by Bitkulov et al., this fact may negatively affect to the CTE [23]. 

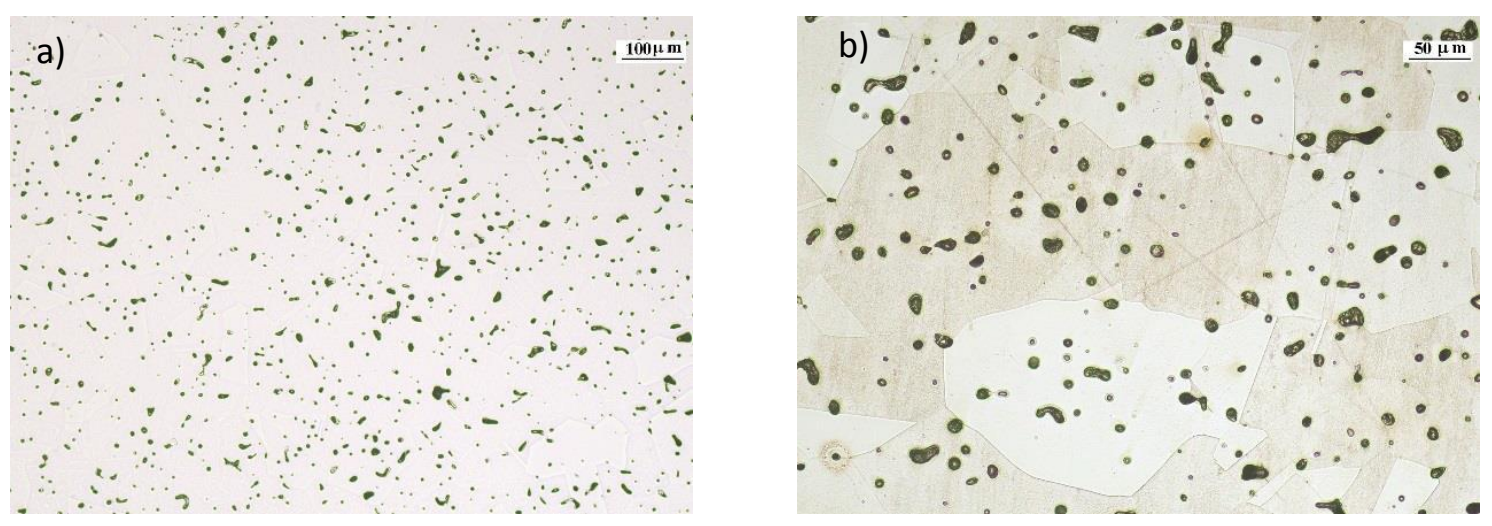

Figure 5. Optical microscope images of the Invar36 part printed at optimum levels: a) polished (at 100 magnification) and b) polished and etched (at 200magnification)

Three CTE cylindric samples, oriented to $\mathrm{X}, \mathrm{Y}$ and $\mathrm{Z}$ axis, were printed at optimum parameter level conditions and then sintered at $1140^{\circ} \mathrm{C}$ during $8 \mathrm{~h}$ under high vacuum. Obtained fractional length changes vs temperature results are plot in Figure 6 , along with CTE values of full dense Invar36 for aerospace applications available in the market [24]. Contrary to Invar36 parts obtained by SLM [2], BJ Invar 36 parts presented an isotropic behaviour, exhibiting practically the same linear expansion properties on the printed 3 directions. This phenomenon seems to be due to the homogeneously distributed equiaxed microstructure obtained by BJ process in contrast to columnar grains that grows along the building direction in SLM process. As expected, a drastic change in the slope of $\Delta \mathrm{L} / \mathrm{L}_{0}$ curve is observed around $250^{\circ} \mathrm{C}$, temperature identified as Curie Temperature. In addition, measured CTE values are completely in line with those presented by full dense commercial Invar36 parts.

a)

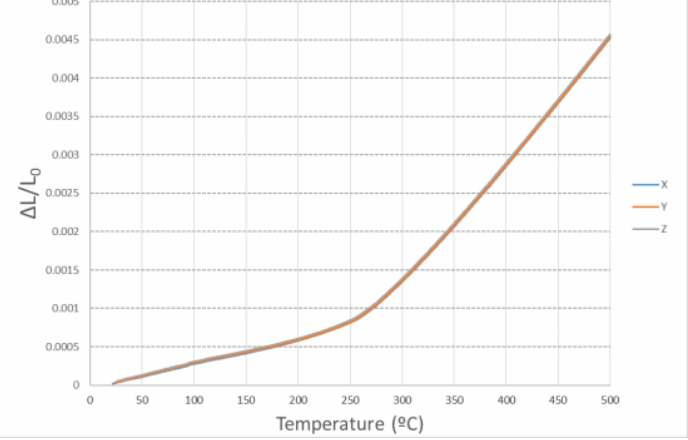

b)

\begin{tabular}{|c|c|c|}
\hline \multirow{2}{*}{$\begin{array}{c}\text { Temperature range } \\
\text { (으) }\end{array}$} & \multicolumn{2}{|c|}{ CTE $\left(\mathbf{1 0}^{-6} \mathbf{~}^{\circ} \mathbf{C}\right)$} \\
\cline { 2 - 3 } & $\begin{array}{c}\text { BJ printed } \\
\text { part }\end{array}$ & $\begin{array}{c}\text { Invar } 36 \\
{[24]}\end{array}$ \\
\hline $25-250$ & $3.490 \pm 0.088$ & 3.5 \\
\hline $25-500$ & $9.488 \pm 0.052$ & 10.1 \\
\hline
\end{tabular}

Figure 6. CTE results: a) $\Delta \mathrm{L} / \mathrm{L}_{0}$ curves for samples printed oriented to $\mathrm{X}, \mathrm{Y}$ and $\mathrm{Z}$ b) comparison of CTE values with commercial Invar36.

\section{Conclusions}

The present work is a preliminary study which opens a new pathway to fabricate high dimensional stability Invar36 for aerospace applications. Taguchi methodology was employed to study and optimise BJ main process parameters to increase the final density of Invar36 printed parts. Obtained results indicate that drying time is the parameter with the higher influence $(77 \%)$ to result variation. Densities up to $92.7 \%$ with a standard deviation of $0.18 \%$ were achieved using the optimal process parameters level concluded from ANOVA results. Printed Invar36 parts presented a homogeneous equiaxial

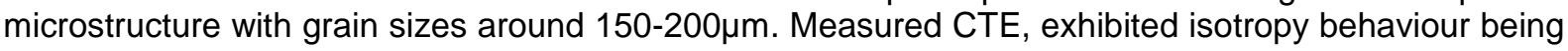
completely comparable to the ones obtained by conventional manufacturing methods. 


\section{References}

[1] Ch.E. Guillaume, Invar, Nature 131 (1933) 658.

[2] Qiu C, Adkins NJE, Attallah MM (2016) Selective laser melting of Invar 36: microstructure and properties. Acta Mater 103:382-395

[3] ASTM F2792-12a, Standard Terminology for Additive Manufacturing Technologies (2011), pp. 1-3.

[4] A.M. Knudson, I.A. Popernack, and A. Schuler, Int. J. Metall. Cast. 10, 111 (2016).

[5] Zhang, S., Miyanaji, H., Yang, L., Ali, A., and Dilip, J. J. S., 2014, "An Experimental Study of ceramic Dental Porcelain Materials Using A 3D Print (3DP) Process," Solid Freeform Fabrication Symposium (SFF), Austin, TX, Aug. 4-6, pp. 991-1011.

[6] Chou, D. T., Wells, D., Hong, D., Lee, B., Kuhn, H., and Kumta, P. N., 2013,"Novel Processing of Iron-Manganese Alloy-Based Biomaterials by Inkjet 3-D Printing," Acta Biomater., 9(10), pp. 8593-8603.

[7] Truong Do, Patrick Kwon,, Chang Seop Shin I.J.M.T.M (2017), "Process development toward fulldensity stainless steel parts with binder jetting printing", International Journal of Machine Tools \& Manufacture 121, pp.50-60.

[8] Verlee, B., Dormal, T. and Lecomte-Beckers, J. (2011), "Properties of Sintered Parts Shaped by 3DPrinting from Bimodal 316L Stainless Steel Powder Mixtures", Euro PM2011, pp. 357-362.

[9] Y. Bai, G. Wagner, C. B. Williams, Effect of Bimodal Powder Mixture on Powder Packing Density and Sintered Density in Binder Jetting of Metals. In Annual International Solid Freeform Fabrication Symposium, (2015) p. 62.

[10] Williams, C. B., Cochran, J. K., and Rosen, D. W., 2011, "Additive Manufacturing of Metallic cellular Materials Via Three-Dimensional Printing," Int. J.Adv. Manuf. Technol., 53(1-4), pp. 231-239.

[11] Holman, R. K., 2001, "Effects of the Polymeric Binder System in Slurry-Based Three Dimensional Printing of Ceramics," Ph.D. thesis, Massachusetts Institute of Technology, Cambridge, MA.

[12] Gaytan, S. M., Cadena, M. A., Karim, H., Delfin, D., Lin, Y., Espalin, D., Mac-Donald, E., and Wicker, R. B., 2015, "Fabrication of Barium Titanate by Binder Jetting Additive Manufacturing Technology," Ceram. Int., 41(5),pp. 6610-6619.

[13] T. J Hsu and W. H. Lai, "Manufacturing parts optimization in the three-dimensional printing process by the Taguchi method", Journal of the Chinese Institute of Engineers, Vol. 33, No. 1, pp. 121-130 (2010).

[14] H. Chen and Y. F. Zhao, "Process parameters optimization for improving surface quality and manufacturing accuracy of binder jetting additive manufacturing process", Rapid Prototyping Journal, Vol. 22, Iss 3.

[15] Gibson, I., D. Rosen, and B. Stucker, Additive manufacturing technologies: 3D Printing. Rapid Prototyping, and Direct Digital Manufacturing, 2015.

[16] Y. Wang and Y. F. Zhao, "Investigation of Sintering Shrinkage in Binder Jetting Additive Manufacturing Process", Procedia Manufacturing 10 (2017) 779-790.

[17] R. K. Roy, "A Primer on the Taguchi Method, Second Edition", Society of Manufacturing Engineers, 2010.

[18] G. E. P. Box, J, S, Hunter and W. G. Hunter, "Statistics for Experimenters: Design, Innovation, and Discovery", Wiley Series in Probability and Statistics, 2005.

[19] E. Sheydaeian, Z. Fishman, M. Vlasea and E. Toyserkani, "On the effect of throughout layer thickness variation on properties of additively manufactured cellular titanium structures", Additive Manufacturing, 18 (2017), 40-47.

[20] R. K. MacGeary, "Mechanical packing of spherical particles", Journal of the American Ceramic Society. 44 (10) (1961) 513-522.

[21] H. Y. Sohn and C. Moreland, "The Effect of Particle Size Distribution on Packing Density", The Canadian Journal of Chemical Engineering. Vol. 46, June, 1968.

[22] T. Do, P. Kwon and C. S. Shin, "Process development toward full-density stainless steel parts with binder jetting printing", International Journal of Machine Tools and Manufacture. 121 (2017) 50-60

[23] Bitkulov, I.K., Burkhanov, A.M., Kazantsev, V.A., Mulyukov, R.R., Mulyukov, K.Y.,Safarov, I.M., 2006. Effect of severe plastic deformation on the properties of the $\mathrm{Fe}-36 \% \mathrm{Ni}$ invar alloy. Physics of Metals and Metallography 102,91-96.

[24] https://www.sandmeyersteel.com/spanish/ssc-invar36.html 